\title{
Ultrasonochemical-Assisted Synthesis of CuO Nanorods with High Hydrogen Storage Ability
}

\author{
Gang Xiao, ${ }^{1}$ Peng Gao, ${ }^{1,2}$ Longqiang Wang, ${ }^{1}$ Yujin Chen, ${ }^{1,2}$ Ying Wang, ${ }^{1}$ and Guoli Zhang1 \\ ${ }^{1}$ College of Materials Science and Chemical Engineering and College of Science, Harbin Engineering University, Heilongjiang, \\ Harbin 150001, China \\ ${ }^{2}$ Key Laboratory of Superlight Materials and Surface Technology, Harbin Engineering University, Ministry of Education, \\ Harbin 150001, China \\ Correspondence should be addressed to Peng Gao, gaopeng@hrbeu.edu.cn
}

Received 21 February 2011; Revised 24 April 2011; Accepted 13 May 2011

Academic Editor: Junliang Zhang

Copyright ( 2011 Gang Xiao et al. This is an open access article distributed under the Creative Commons Attribution License, which permits unrestricted use, distribution, and reproduction in any medium, provided the original work is properly cited.

Uniform $\mathrm{CuO}$ nanorods with different size have been synthesized in a water-alcohol solution through a fast and facile ultrasound irradiation assistant route. Especially, the as-prepared $\mathrm{CuO}$ nanorods have shown a strong size-induced enhancement of electrochemical hydrogen storage performance and exhibit a notable hydrogen storage capacity and big BET surface area. These results further implied that the as-prepared $\mathrm{CuO}$ nanorods could be a promising candidate for electrochemical hydrogen storage applications. The observation of the comparison experiments with different concentrations of $\mathrm{NaOH}$, ethanol, CTAB, and HTMA while keeping other synthetic parameters unchanged leads to the morphology and size change of $\mathrm{CuO}$ products.

\section{Introduction}

It is widely accepted that the properties of nanomaterials are not only closely related to their sizes but also to their shapes. Therefore, controlling the morphologies of nanomaterials is one of the most important issues and effective ways to obtain desirable properties. one-dimensional (1D) nanoscaled materials such as carbon nanotubes (CNTs) [1], semiconductor nanowires, and nanobelts [2-7] exhibit interesting and useful properties and may be applied as building blocks for the integration of the next generation of nanoelectronics, ultrasmall optical devices, biosensors, and so forth. As a p-type semiconductor with a narrow band gap $(1.2 \mathrm{eV}), \mathrm{CuO}$ nanomaterials have been widely exploited for diverse applications, such as heterogeneous catalysts [8-10], photoelectrochemical materials [11], gas sensors [12], lithium ion electrode materials [13], electrochemical hydrogen storage materials [14], and field emission (FE) emitters $[15,16]$. Many recent efforts have been directed toward the fabrication of nanostructured $\mathrm{CuO}$ to enhance its performance in currently existing applications. In particular, a variety of $1 \mathrm{D} \mathrm{CuO}$ nanostructures have been prepared by high-temperature approaches [17-25] and low-temperature wet chemical approaches [26-32]. Generally, the abovementioned methods for $1 \mathrm{D} \mathrm{CuO}$ nanomaterials require high temperature or additional templates to act as a support and are constrained by expense and complex. Comparatively, the ultrasonic approach was more attractive for both its simplicity and commercial feasibility. Different from other traditional chemical methods, the sonochemistry route is based on acoustic cavitations through the formation, growth, and collapse of bubbles in the liquid. The implosive collapse is an adiabatic process, which generates localized hot spots with transient temperatures of 5000-25000 K, pressures of about $1800 \mathrm{~atm}[33,34]$, and heating and cooling rates in excess of $1010 \mathrm{~K} / \mathrm{s}[35,36]$. These extreme conditions have been applied to prepare amorphous metals, carbides, oxides, sulfides, and so forth in various media [37-41].

Herein, we present a fast and facile ultrasound (US) irradiation assistant route to mass-synthesize uniform $\mathrm{CuO}$ nanorods with different size in a water-alcohol solution. Especially, the as-prepared $\mathrm{CuO}$ nanorods have shown a strong size-induced enhancement of electrochemical hydrogen storage performance and exhibit a notable hydrogen storage capacity and big BET surface area. These results further implied that the as-prepared $\mathrm{CuO}$ nanorods could be 
TABLE 1: The comparison experiments with different concentrations of $\mathrm{NaOH}$, ethanol, CTAB, and HTMA.

\begin{tabular}{cccccc}
\hline Sample no. & $\mathrm{CuAC}_{2} \cdot \mathrm{H}_{2} \mathrm{O}(\mathrm{g})$ & $0.5 \mathrm{M} \mathrm{NaOH}(\mathrm{mL})$ & Ethanol $(\mathrm{mL})$ & $\mathrm{H}_{2} \mathrm{O}(\mathrm{mL})$ & $\mathrm{CTAB}(\mathrm{C})$ or $\mathrm{HTMA}(\mathrm{H})(\mathrm{g})$ \\
\hline 1 & 0.11 & 4 & 15 & 35 & $0.3(\mathrm{C})$ \\
2 & 0.11 & 8 & 50 & 35 & $0.3(\mathrm{C})$ \\
3 & 0.11 & 4 & 15 & 35 & $0.2(\mathrm{C})$ \\
4 & 0.11 & 4 & 15 & 25 & $0.3(\mathrm{H})$ \\
5 & 0.11 & 4 & 25 & 0 & $0.3(\mathrm{H})$ \\
6 & 0.11 & 4 & 50 & 35 & $0.2(\mathrm{H})$ \\
7 & 0.11 & 4 & 15 & 35 & $0.1(\mathrm{H})$ \\
8 & 0.11 & 4 & 15 & \\
\hline
\end{tabular}

a promising candidate for electrochemical hydrogen storage applications.

\section{Experimental}

In a typical experiment, all of the chemicals were of analytical grade and were used as received. Aqueous solutions were prepared using distilled water. Firstly, $0.11 \mathrm{~g} \mathrm{CuAC} \cdot \mathrm{H}_{2} \mathrm{O}$ was dissolved in the solution mixed with $15 \mathrm{~mL}$ ethanol and $35 \mathrm{~mL}$ distilled water in a $100 \mathrm{~mL}$ beaker. Then $8 \mathrm{~mL}$ $\mathrm{NaOH}$ aqueous solution $(0.5 \mathrm{M})$ and $0.3 \mathrm{~g}$ CTAB were added slowly. After that, the solution was kept under US irradiation at room temperature for 45 minutes. Finally, the obtained precipitates were collected and washed several times with absolute ethanol and distilled water. The comparison experiments with different concentrations of $\mathrm{NaOH}$, ethanol, CTAB, and HTMA have also been conducted as listed in Table 1.

$\mathrm{X}$-ray powder diffraction (XRD) analysis was carried out with a Japan Rigaku D/max-rA X-ray diffractometer with graphite monochromatized $\mathrm{Cu} K \alpha$ radiation $(\lambda=1.54178 \AA)$. The scan rate of $0.05^{\circ} \mathrm{s}$ was used to record the patterns in the $2 \theta$ range of $20-70^{\circ}$. SEM image was obtained by a JSM-6700 F field emission scanning electron microanalyser (JEOL, Japan), whereby the resulting powder was mounted on a copper slice. HRTEM images were recorded on a JEOL2010 TEM at an acceleration voltage of $200 \mathrm{KV}$. The porous nature of the nanorods was further confirmed by the measurement of the pore size distribution, which was obtained by the nitrogen adsorption-desorption isotherm and BarrettJoyner-Halenda (BJH) methods on an OMNISORP-100CX accelerated surface area and porosimetry system. The electrochemical measurements were carried out following the method reported in [14] with slight modification. Briefly, the electrode was fabricated by directly pressing the synthesized $\mathrm{CuO}$ powders on a sheet of nickel foam at $50 \mathrm{MPa}$. All of the experiments were performed in a three-electrode cell in $6 \mathrm{M} \mathrm{KOH}$ at $25^{\circ} \mathrm{C}$ under normal atmosphere. The $\mathrm{CuO}$ nanostructures were used as the working electrode, $\mathrm{Ni}(\mathrm{OH})_{2} / \mathrm{NiOOH}$ as the counterelectrode, and $\mathrm{Ag} / \mathrm{AgCl}$ as a reference electrode. The $\mathrm{CuO}$ nanostructures electrode was charged for $3 \mathrm{~h}$ at a current density after a $2 \mathrm{~s}$ rest. All of the electrochemical hydrogen storage experiments were carried out using the Land battery system (CT2001A) at room temperature.

\section{Results and Discussion}

The overall crystallinity and purity of the as-synthesized samples were investigated by XRD and HRTEM measurement. As shown in Figure 1(a), all the indexed diffraction peaks in the XRD pattern show the presence of monoclinic $\mathrm{CuO}$ (spacegroup: $\mathrm{C}_{2} / \mathrm{c}$ ) with lattice constants $a=4.69 \AA$, $b=3.42 \AA$, and $c=5.13 \AA$, which is in good agreement with the literature values for the bulk CuO (JCPDS, 41-0254). The above result also indicates that the products obtained here are fully monoclinic $\mathrm{CuO}$ with high purity and crystalline quality, which is further proved by the HRTEM investment, as shown in Figures 1(c) and 1(d). Figures 1(b) and 1(c) show the large-scale $\mathrm{CuO}$ nanorods obtained, from which it can be seen that the nanorod is more than $200 \mathrm{~nm}$ long and $10 \mathrm{~nm}$ in diameter, and a high yield (>95\%) of this $1 \mathrm{D}$ form can be easily observed. The HRTEM image in Figure $1(d)$ indicates that the nanorod is of single crystal and can be indexed as the monoclinic $\mathrm{CuO}$ phase, which is in accord with the XRD result. As shown in Figure $1(\mathrm{~d})$, the lattice interplanar spacing has been determined to be $2.76 \AA$, corresponding to the (110) plane of monoclinic $\mathrm{CuO}$, which suggests that the nanorods grow preferentially through (110) plane stacking.

The measurement of $\mathrm{BJH}$ methods showed that the BET surface area of $\mathrm{CuO}$ nanorods was $49.8 \mathrm{~m}^{2} / \mathrm{g}$, which implied that the $\mathrm{CuO}$ nanorods obtained here were a kind of potential porous material, as shown in Figure 2(a). Further study of the pore size distributions of the sample is illustrated in Figure 2(b). The Curve shows the relative pore volume distributions according to the average size of pores, in which there is a distribution centered around $40 \mathrm{~nm}$. Interestingly, the electrochemical study demonstrated that the discharge capacity of $\mathrm{CuO}$ nanorods displayed a noticeable electrochemical hydrogen storage ability ( $165 \mathrm{mAh} / \mathrm{g}$ ), which amounts to the $32.8 \%$ hydrogen storage capacity of SWNTs, whose discharge capacity is $503 \mathrm{mAh} / \mathrm{g}$, corresponding to $1.84 \mathrm{wt} \%$ hydrogen [42]. In the charge curve of $\mathrm{CuO}$ nanorods, as shown in Figure 2(c), with the increase of the electrochemical capacity, the potential increases quickly but remains unchanged when the charge capacity reaches $3 \mathrm{mAh} / \mathrm{g}$. One new obvious plateau of potential is observed between $5 \mathrm{mAh} / \mathrm{g}$ and $170 \mathrm{mAh} / \mathrm{g}$. This indicates that two different hydrogen adsorption sites [42] exist in the synthesized $\mathrm{CuO}$ nanorods; in other words, 


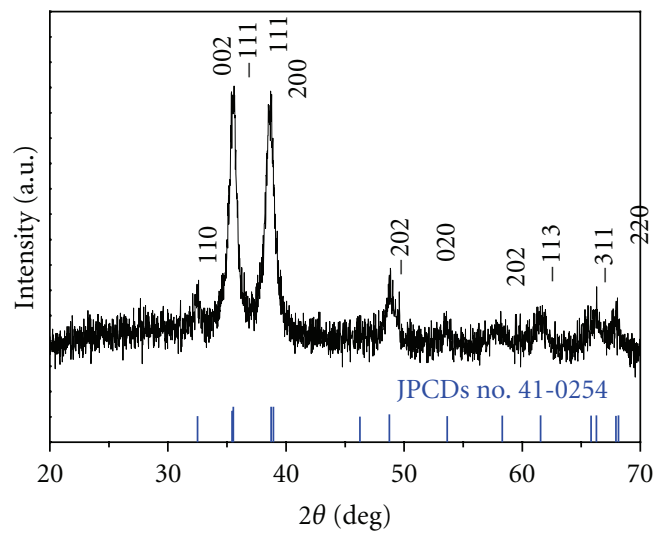

(a)

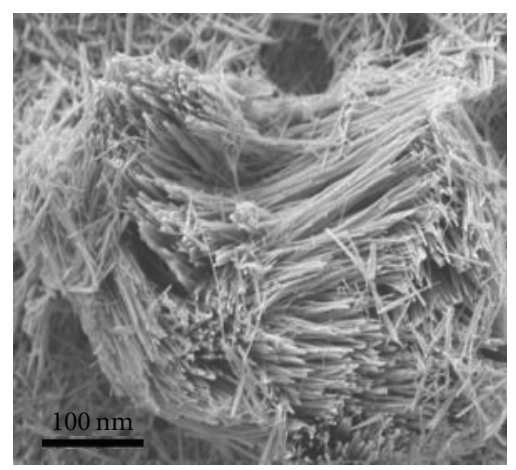

(b)

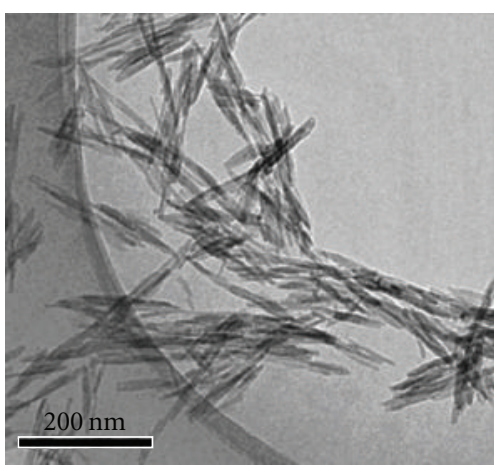

(c)

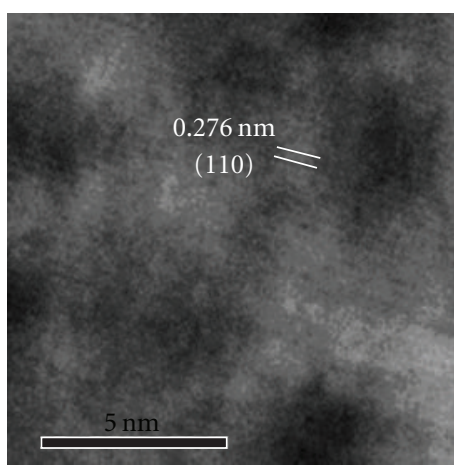

(d)

FIGURE 1: (a) and (b) XRD pattern and SEM image of as-obtained product. (c) and (d) TEM images, HRTEM image of the as-prepared CuO nanorods.

there are two different electrochemical steps in the charging process. The reaction is expressed as follows:

$$
\begin{aligned}
\mathrm{CuO} \text { nanorods } & +\mathrm{H}_{2} \mathrm{O}+\mathrm{e} \\
& \longrightarrow \mathrm{CuO} \text { nanorods } / \mathrm{H}_{\text {surface }}+\mathrm{OH}^{-}
\end{aligned}
$$

$\mathrm{CuO}$ nanorods $/ \mathrm{H}_{\text {surface }} \longrightarrow \mathrm{CuO}$ nanorods $/ \mathrm{H}_{\text {interstitial }}$.

It is assumed that the $\mathrm{H}$ was first adsorbed onto the surface of each nanorod and then diffused into the interstitial sites among $\mathrm{CuO}$. The discharge curve also displays two different hydrogen release processes, which further confirms the above results. The cycle life of $\mathrm{CuO}$ nanorod electrode is shown in Figure 2(d). After being cycled 50 times at the charge-discharge current density of $30 \mathrm{~mA} / \mathrm{g}$, the discharging capacities of $\mathrm{CuO}$ nanobelts remain over $20 \mathrm{mAh} / \mathrm{g}$. Compared with the capacities $(100 \mathrm{mAh} / \mathrm{g}$ and $130 \mathrm{mAh} / \mathrm{g})$ of other $1 \mathrm{D} \mathrm{CuO}$ nanostructures obtained by us, as shown in Figures 2(e) and 2(f) and Figures 3(a), 3(c), and 3(d), the as-prepared $\mathrm{CuO}$ nanorods exhibited higher capacity. The relatively high capacity was considered to be pertinent to the enhanced electrocatalytic activity of the highly porous and layered structures of the synthesized $\mathrm{CuO}$ nanorods. And we believe that the investigations of electrochemical hydrogen storage of $\mathrm{CuO}$ nanostructures help us to understand the relationship between morphology, size, and properties and thus inspire us to explore new nanostructures with higher hydrogen uptake.

Comparison experiments with different concentrations of $\mathrm{NaOH}$, ethanol, and $\mathrm{CTAB}$ while keeping other synthetic parameters unchanged leads to the morphology and size change of $\mathrm{CuO}$ products. As shown in Figures 3(a) and 3(b), when the $\mathrm{NaOH}$ concentrations were reduced, $\mathrm{CuO}$ nanorod bundles composed of rods with smaller size (several nanometers) were obtained. When the ethanol concentrations were increased, short $\mathrm{CuO}$ nanorods ( $\sim 50 \mathrm{~nm}$ long) formed, as shown in Figures 3(c) and 3(d). CuO nanorod bundles were also produced when the CTAB mount was reduced or free, as shown in Figures 3(e) and 3(f). When using other surface active reagent (such as hexamethylene tetramine (HTMA)) instead of CTAB, different $\mathrm{CuO}$ 1D nanostructures have also been prepared, as shown in Figure 4. Therefore, suitable thermodynamic experimental conditions favor the oriented crystalline growth process of the $\mathrm{CuO}$ nanorods. It is also implied that different shapely $\mathrm{CuO}$ nanostructures can be controllably synthesized through adjusting the reaction parameters of this US chemical reaction process. 


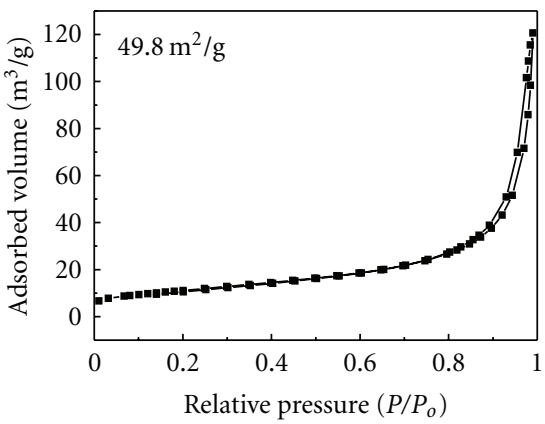

(a)

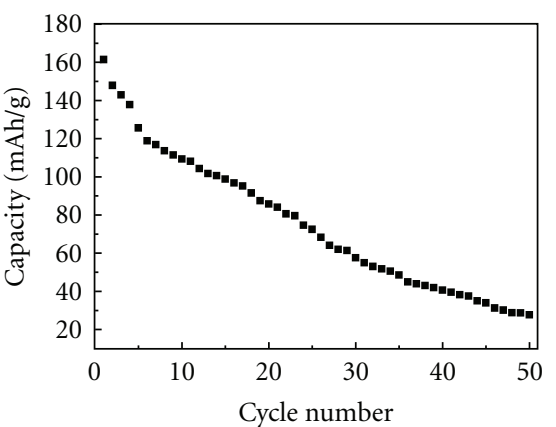

(d)

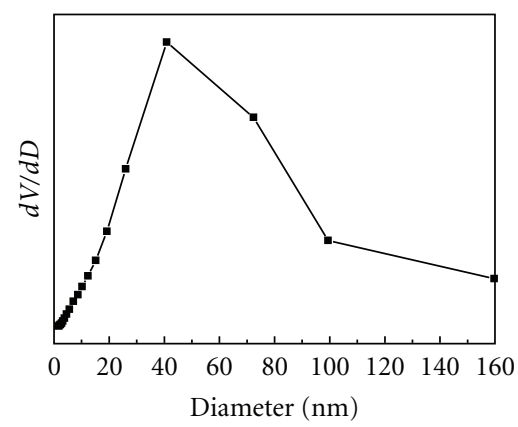

(b)

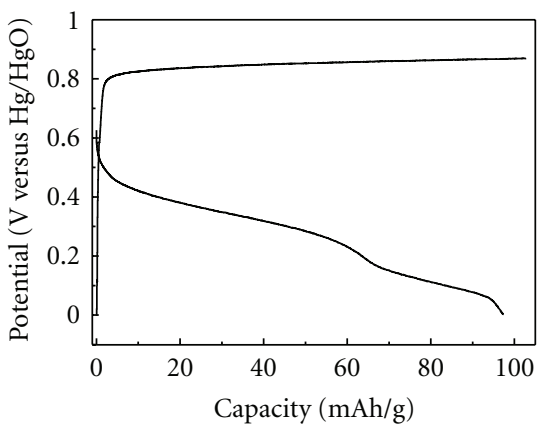

(e)

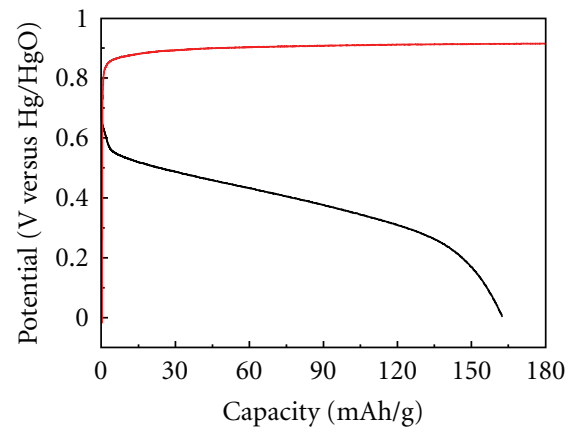

(c)

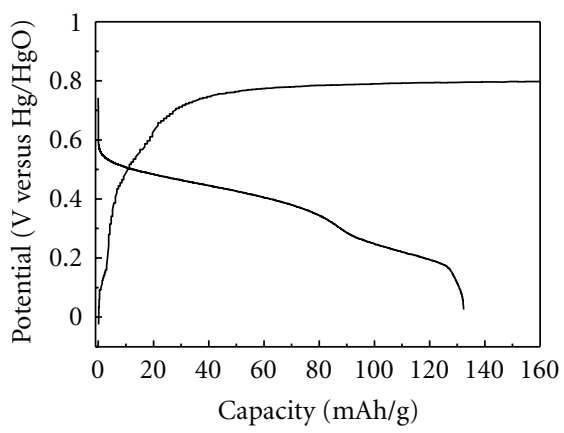

(f)

Figure 2: (a) $\mathrm{N}_{2}$ adsorption-desorption isotherm of the as-obtained $\mathrm{CuO}$ nanorods. (b) Pore-size distribution curve obtained from the desorption data. (c) Charge-discharge curves of $\mathrm{CuO}$ nanorods at a constant current density of $30 \mathrm{~mA} / \mathrm{g}$. (d) Cycle life of the as-synthesized $\mathrm{CuO}$ nanorod electrode. (e) and (f) Charge-discharge curves of $\mathrm{CuO}$ nanorod bundles obtained by adding $4 \mathrm{~mL} \mathrm{NaOH}$ while keeping other reaction conditions unchanged and $1 \mathrm{D} \mathrm{CuO}$ nanostructures obtained when $50 \mathrm{~mL}$ ethanol were added at a constant current density of $30 \mathrm{~mA} / \mathrm{g}$.

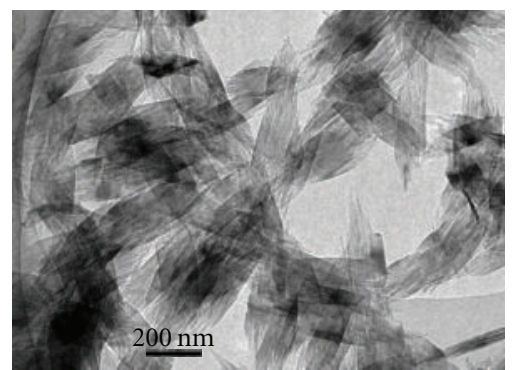

(a)

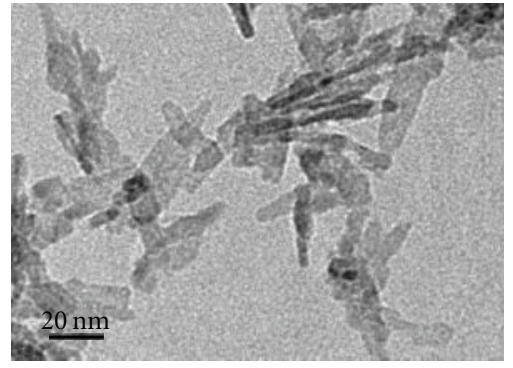

(d)

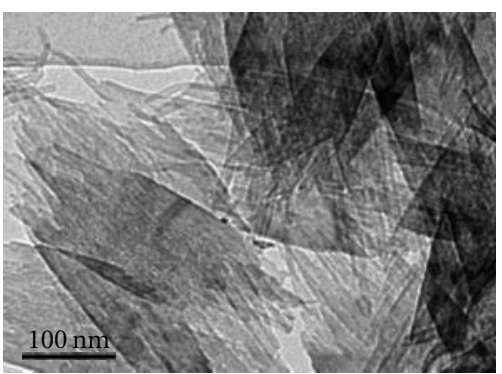

(b)

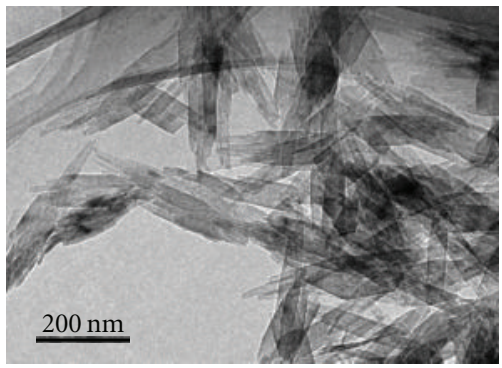

(e)

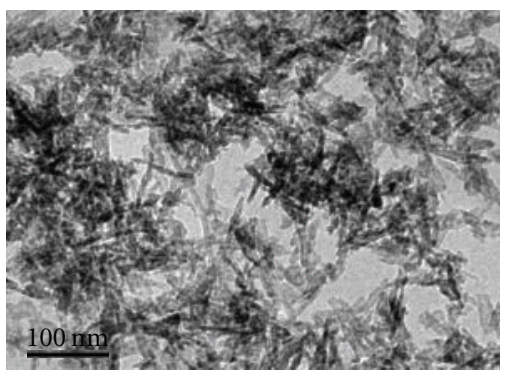

(c)

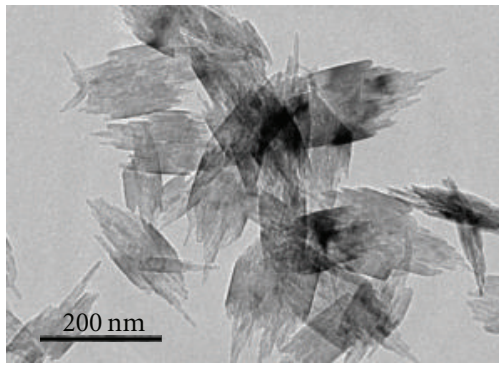

(f)

Figure 3: (a) and (b) TEM images of sample 1. (c) and (d) TEM images of sample 2. (e) and (f) TEM images of sample 3 and sample 4. The samples' reaction conditions have been listed in Table 1. 


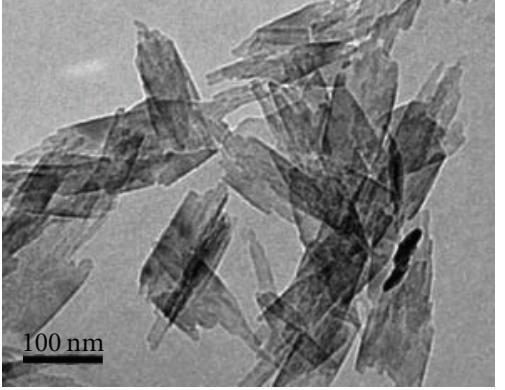

(a)

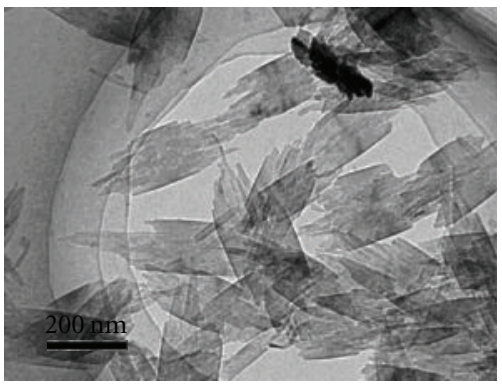

(c)

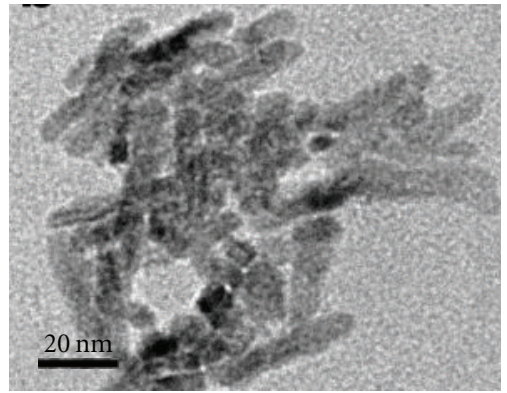

(b)

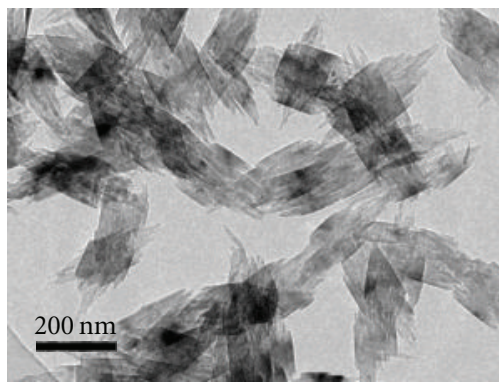

(d)

Figure 4: TEM images of sample 5, 6, 7, and 8 as listed in Table 1.

\section{Conclusions}

In summary, $\mathrm{CuO}$ nanorods were synthesized through a fast and facile ultrasound irradiation assistant route. The products exhibit excellent hydrogen storage capacity and big $\mathrm{BET}$ surface area. Different shapely $\mathrm{CuO}$ nanostructures have been controllably synthesized. The comparison experiments show that the reactant concentrations are critical to the formation of $1 \mathrm{D} \mathrm{CuO}$ nanostructures. Further research will be performed on more novel cupreous 1D nanostructures exhibiting different electrochemical hydrogen storage performances, in which more excellent hydrogen storage materials might be found.

\section{Acknowledgments}

The authors thank the Natural Science Foundation of Heilongjiang Province, China (nos. E200839 and F200828), the Natural Science Foundation of China (Grant nos. 21001035 and 51072038), the Specialized Research Fund for the Doctoral Program of Higher Education of China (no. 20092304120021), Harbin Key Sci-tech Project (no. 2010AA4BG004), Research Fund of Heilongiiang Provincial Education Department (no. 11551418), and the Fundamental Research funds for the Central Universities (no. HEUCF101016 and no. HEUCFT1010), Outstanding Youth Foundation of Heilongiiang Province (Grant no. JC201008), for the financial support of this research.

\section{References}

[1] S. Iijima, "Helical microtubules of graphitic carbon," Nature, vol. 354 , no. 6348 , pp. 56-58, 1991.
[2] Y. Xia and P. Yang, "Chemistry and physics of nanowires," Advanced Materials, vol. 15, no. 5, pp. 351-352, 2003.

[3] Z. L. Wang, X. Wang, P. Gao, J. Li, and C. J. Summers, "Rectangular porous $\mathrm{ZnO}-\mathrm{ZnS}$ nanocables and $\mathrm{ZnS}$ nanotubes," Advanced Materials, vol. 14, no. 23, pp. 1732-1735, 2002.

[4] C. Ma, D. Moore, J. Li, and Z. L. Wang, "Nanobelts, nanocombs, and nanowindmills of wurtzite ZnS," Advanced Materials, vol. 15, no. 3, pp. 228-231, 2003.

[5] P. Gao, M. Zhang, Z. Niu, and Q. Xiao, "A facile solutionchemistry method for $\mathrm{Cu}(\mathrm{OH})_{2}$ nanoribbon arrays with noticeable electrochemical hydrogen storage ability at room temperature," Chemical Communications, no. 48, pp. 5197-5199, 2007.

[6] P. Gao, Y. Chen, Y. Wang, Q. Zhang, X. Li, and M. Hu, "A simple recycling and reuse hydrothermal route to $\mathrm{ZnO}$ nanorod arrays, nanoribbon bundles, nanosheets, nanocubes and nanoparticles," Chemical Communications, no. 19, pp. 27622764, 2009.

[7] H. Men, P. Gao, B. Zhou et al., "Fast synthesis of ultrathin $\mathrm{ZnSnO}_{3}$ nanorods with high ethanol sensing properties," Chemical Communications, vol. 46, no. 40, pp. 7581-7583, 2010.

[8] J. B. Reitz and E. I. Solomon, "Propylene oxidation on copper oxide surfaces: electronic and geometric contributions to reactivity and selectivity," Journal of the American Chemical Society, vol. 120, no. 44, pp. 11467-11478, 1998.

[9] J. A. Switzer, H. M. Kothari, P. Poizot, S. Nakanishi, and E. W. Bohannan, "Enantiospecific electrodeposition of a chiral catalyst," Nature, vol. 425, no. 6957, pp. 490-493, 2003.

[10] F. Mariño, G. Baronetti, M. Laborde et al., "Optimized CuO$\mathrm{CeO}_{2}$ catalysts for COPROX reaction," International Journal of Hydrogen Energy, vol. 33, no. 4, pp. 1345-1353, 2008.

[11] Y. S. Chaudhary, A. Agrawal, R. Shrivastav, V. R. Satsangi, and S. Dass, "A study on the photoelectrochemical properties 
of copper oxide thin films," International Journal of Hydrogen Energy, vol. 29, no. 2, pp. 131-134, 2004.

[12] A. Chowdhuri, V. Gupta, K. Sreenivas, R. Kumar, S. Mozumdar, and P. K. Patanjali, "Response speed of $\mathrm{SnO}_{2}$-based $\mathrm{H}_{2} \mathrm{~S}$ gas sensors with $\mathrm{CuO}$ nanoparticles," Applied Physics Letters, vol. 84, no. 7, pp. 1180-1182, 2004.

[13] X. P. Gao, J. L. Bao, G. L. Pan et al., "Preparation and electrochemical performance of polycrystalline and single crystalline $\mathrm{CuO}$ nanorods as anode materials for $\mathrm{Li}$ ion battery," Journal of Physical Chemistry B, vol. 108, no. 18, pp. 5547-5551, 2004.

[14] P. Gao, Y. Chen, H. Lv, X. Li, Y. Wang, and Q. Zhang, "Synthesis of $\mathrm{CuO}$ nanoribbon arrays with noticeable electrochemical hydrogen storage ability by a simple precursor dehydration route at lower temperature," International Journal of Hydrogen Energy, vol. 34, no. 7, pp. 3065-3069, 2009.

[15] C. T. Hsieh, J. M. Chen, H. H. Lin, and H. C. Shih, "Field emission from various Cuo nanostructures," Applied Physics Letters, vol. 83, no. 16, pp. 3383-3385, 2003.

[16] S. Z. Deng, N. S. Xu, W. Zhang, X. Wen, and S. Yang, "Temperature dependence of field emission from cupric oxide nanobelt films," Applied Physics Letters, vol. 83, no. 4, pp. 746748, 2003.

[17] C. R. Martin, "Nanomaterials: a membrane-based synthetic approach," Science, vol. 266, no. 5193, pp. 1961-1966, 1994.

[18] M. H. Huang, A. Choudrey, and P. Yang, "Ag nanowire formation within mesoporous silica," Chemical Communications, no. 12, pp. 1063-1064, 2000.

[19] T. Seeger, P. Kohler-Redlich, and M. Rühle, "Synthesis of nanometer-sized $\mathrm{SiC}$ whiskers in the arc-discharge," Advanced Materials, vol. 12, no. 4, pp. 279-282, 2000.

[20] C. Tang, S. Fan, M. L. de la Chapelle, H. Dang, and P. Li, "Synthesis of gallium phosphide nanorods," Advanced Materials, vol. 12, no. 18, pp. 1346-1348, 2000.

[21] S. Bhattacharrya, S. K. Saha, and D. Chakravorty, "Nanowire formation in a polymeric film," Applied Physics Letters, vol. 76, no. 26, pp. 3896-3898, 2000.

[22] S. Liu, J. Yue, and A. Gedanken, "Synthesis of long silver nanowires from $\mathrm{AgBr}$ nanocrystals," Advanced Materials, vol. 13, no. 9, pp. 656-658, 2001.

[23] S. Bhattacharyya, S. K. Saha, and D. Chakravorty, "Silver nanowires grown in the pores of a silica gel," Applied Physics Letters, vol. 77, no. 23, pp. 3770-3772, 2000.

[24] N. R. Jana, L. Gearheart, and C. J. Murphy, "Wet chemical synthesis of silver nanorods and nanowires of controllable aspect ratio," Chemical Communications, no. 7, pp. 617-618, 2001.

[25] S. Iijima, "Helical microtubules of graphitic carbon," Nature, vol. 354, no. 6348, pp. 56-58, 1991.

[26] A. M. Morales and C. M. Lieber, "A laser ablation method for the synthesis of crystalline semiconductor nanowires," Science, vol. 279, no. 5348, pp. 208-211, 1998.

[27] P. Yan, Y. Xie, Y. Qian, and X. Liu, "A cluster growth route to quantum-confined CdS nanowires," Chemical Communications, no. 14, pp. 1293-1294, 1999.

[28] M. S. Gudiksen and C. M. Lieber, "Diameter-selective synthesis of semiconductor nanowires," Journal of the American Chemical Society, vol. 122, no. 36, pp. 8801-8802, 2000.

[29] T. J. Trentler, K. M. Hickman, S. C. Goel, A. M. Viano, P. C. Gibbons, and W. E. Buhro, "Solution-liquid-solid growth of crystalline III-V semiconductors: an analogy to vapor-liquidsolid growth," Science, vol. 270, no. 5243, pp. 1791-1794, 1995.
[30] B. Gates, Y. Yin, and Y. Xia, "A solution-phase approach to the synthesis of uniform nanowires of crystalline selenium with lateral dimensions in the range of 10-30 nm," Journal of the American Chemical Society, vol. 122, no. 50, pp. 12582-12583, 2000.

[31] Y. Wu and P. Yang, "Germanium nanowire growth via simple vapor transport," Chemistry of Materials, vol. 12, no. 3, pp. 605-607, 2000.

[32] K. Soulantica, A. Maisonnat, F. Senocq, M.-C. Fromen, M.J. Casanove, and B. Chaudret, "Selective synthesis of novel In and In3Sn nanowires by an organometallic route at room temperature," Angewandte Chemie, vol. 113, no. 16, pp. 30713074, 2001.

[33] K. S. Suslick, S. B. Choe, A. A. Cichowlas, and M. W. Grinstaff, "Sonochemical synthesis of amorphous iron," Nature, vol. 353, no. 6343, pp. 414-416, 1991.

[34] K. S. Suslick, D. A. Hammerton, and R. E. Cline, "The sonochemical hot spot," Journal of the American Chemical Society, vol. 108, no. 18, pp. 5641-5642, 1986.

[35] B. P. Barber and S. J. Putterman, "Observation of synchronous picosecond sonoluminescence," Nature, vol. 352, no. 6333, pp. 318-320, 1991.

[36] R. Hiller, S. J. Putterman, and B. P. Barber, "Spectrum of synchronous picosecond sonoluminescence," Physical Review Letters, vol. 69, no. 8, pp. 1182-1184, 1992.

[37] G. Z. Wang, B. Y. Geng, X. M. Huang, Y. W. Wang, G. H. Li, and L. D. Zhang, "A convenient ultrasonic irradiation technique for in situ synthesis of zinc sulfide nanocrystallites at room temperature," Applied Physics A, vol. 77, no. 7, pp. 933936, 2003.

[38] J. Yin, X. Qian, J. Yin, M. Shi, and G. Zhou, "Preparation of ZnS/PS microspheres and ZnS hollow shells," Materials Letters, vol. 57, no. 24-25, pp. 3859-3863, 2003.

[39] H. Wang, Y. N. Lu, J. J. Zhu, and H. Y. Chen, "Sonochemical fabrication and characterization of stibnite nanorods," Inorganic Chemistry, vol. 42, no. 20, pp. 6404-6411, 2003.

[40] J. H. Zhang, Z. Chen, Z. L. Wang, and N. B. Ming, "Sonochemical method for the synthesis of antimony sulfide microcrystallites with controllable morphology," Journal of Materials Research, vol. 18, no. 8, pp. 1804-1808, 2003.

[41] A. Gedanken, "Using sonochemistry for the fabrication of nanomaterials," Ultrasonics Sonochemistry, vol. 11, no. 2, pp. 4755, 2004.

[42] G. P. Dai, C. Liu, M. Liu, M. Z. Wang, and H. M. Cheng, "Electrochemical hydrogen storage behavior of ropes of aligned single-walled carbon nanotubes," Nano Letters, vol. 2, no. 5, pp. 503-506, 2002. 

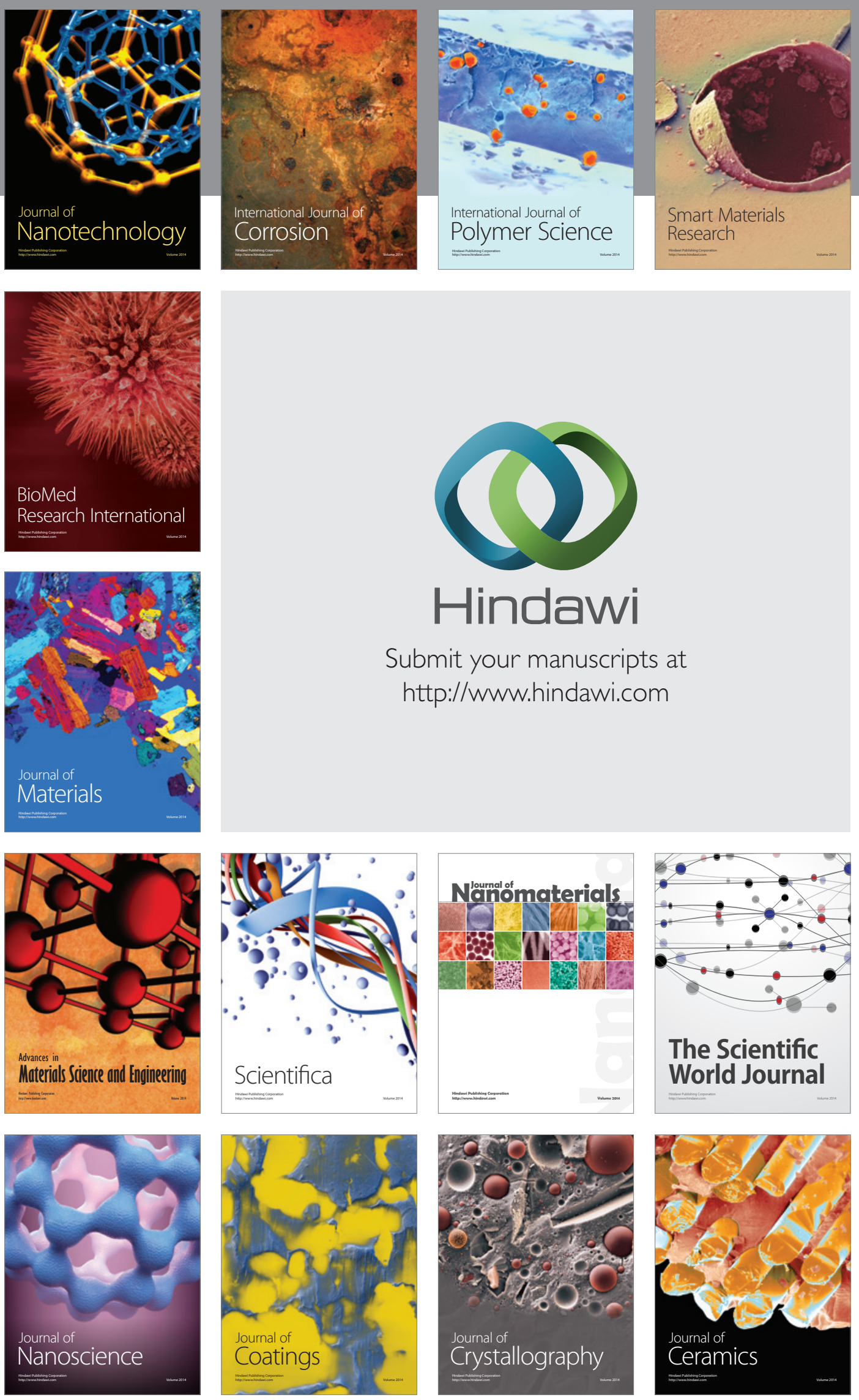

The Scientific World Journal

Submit your manuscripts at

http://www.hindawi.com

\section{World Journal}

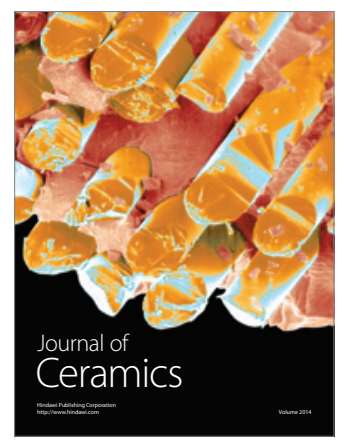

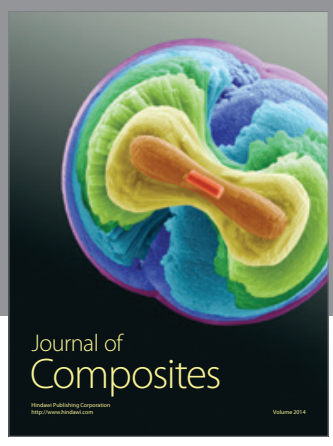
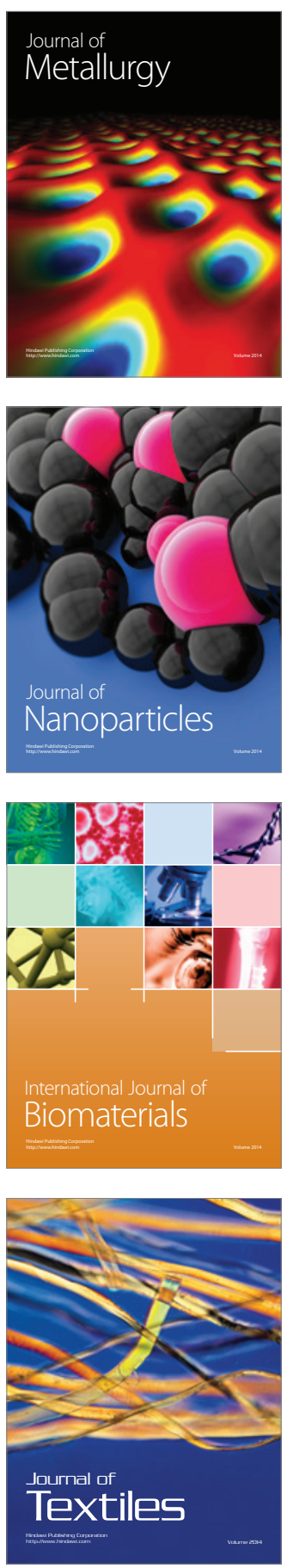